\title{
DnaK and DnaJ heat shock proteins participate in protein export in Escherichia coli
}

\author{
Jadwiga Wild, ${ }^{1}$ Elliot Altman, ${ }^{2}$ Takashi Yura, ${ }^{3}$ and Carol A. Gross ${ }^{4}$ \\ ${ }^{1}$ Department of Bacteriology, University of Wisconsin-Madison, Madison, Wisconsin 53706 USA; ${ }^{2}$ Elliot Altman, \\ Department of Biology, University of Utah, Salt Lake City, Utah 84112 USA; ${ }^{3}$ Institute for Virus Research, Kyoto \\ University, Kyoto, Japan
}

In Escherichia coli secreted proteins must be maintained in an export-competent state before translocation across the cytoplasmic membrane. This function is carried out by a group of proteins called chaperones. SecB is the major chaperone that interacts with precursor proteins before their secretion. We report results indicating that the DnaK and DnaJ heat shock proteins are also involved in the export of several proteins, most likely by acting as their chaperones. Translocation of alkaline phosphatase, a SecB-independent protein, was inhibited in $\mathrm{dnaK}^{-}$and $\mathrm{dnaJ}^{-}$mutant strains, suggesting that export of this protein probably involves DnaK and DnaJ. In addition, DnaK and DnaJ play a critical role in strains lacking SecB. They are required both for viability and for the residual processing of the SecB-dependent proteins LamB and maltose-binding protein (MBP) seen in $\operatorname{secB}$ null strains. Furthermore, overproduction of DnaK and DnaJ permits strains lacking SecB to grow in rich medium and accelerates the processing of LamB and MBP. These results suggest that under conditions where SecB becomes limiting, DnaK and DnaJ probably substitute for SecB and facilitate protein export. This provides the cell with a mechanism to overcome a temporary imbalance in the secretion process caused by an abrupt expansion in the pool of precursor proteins.

[Key Words: DnaK; Hsp70; protein export; chaperones; alkaline phosphatase; SecB]

Received March 23, 1992; revised version accepted April 22, 1992.

Proteins with an ultimate destination of the periplasm or outer membrane in Escherichia coli are synthesized as precursor proteins with an amino-terminal signal sequence. Interaction with cellular chaperones maintains these precursor proteins in a translocation-competent conformation until they are transported through the inner membrane by the translocase. As the precursor proteins enter the periplasm, the signal sequence is removed by signal peptidase, an integral membrane protein with the active site facing the periplasm. The resulting mature protein is distinguished from its cytoplasmic precursor by a small decrease in molecular weight /for review, see Saier et al. 1989; Schatz and Beckwith 1990; W. Wickner et al. 1991).

Some periplasmic and outer membrane precursor proteins interact with the $\mathrm{SecB}$ chaperone, a $16-\mathrm{kD}$ protein that functions as a tetramer (Kumamoto 1989; Watanabe and Blobel 1989). Mutations in $\sec B$, first reported by Kumamoto and Beckwith (1983), decrease export of the periplasmic maltose-binding protein $(\mathrm{MBP})$ and the outer membrane proteins OmpA, OmpF, and LamB. SecB plays a dual role in the translocation process of these proteins. It interacts with partially unfolded precursor proteins to

${ }^{4}$ Corresponding author. maintain them in a translocation-competent conformation /Collier et al. 1988; Kumamoto and Gannon 1988; Weiss et al. 1988; Kumamoto 1989; Weiss and Bassford 1990; Lecker et al. 1990; Hardy and Randall 1991) and binds to SecA, the peripheral membrane component of the translocase (Hartl et al. 1990). This interaction complements that of SecA with the precursor protein itself. Together, these interactions result in positioning precursor proteins at the membrane sites where the integral membrane components of translocase, SecY and SecE, are located (Bieker and Silhavy 1990). Activation of the SecA translocation ATPase then provides the energy for transport through the membrane (Lill et al. 1989, 1990). Two other integral membrane proteins, SecD and SecF, also participate in the translocation process (Gardel et al. 1990; Schatz and Beckwith 1990|, although their mode of action is not understood at present.

Some proteins are exported independently of SecB, although interaction with the rest of the cellular export apparatus is required. Among these are alkaline phosphatase $(\mathrm{AP})$, ribose-binding protein $(\mathrm{RBP}), \beta$-lactamase, and the outer membrane lipoprotein (Kumamoto and Beckwith 1983, 1985; Collier et al. 1988). Several of the heat shock proteins (HSPs) have been shown to function as chaperones, most notably GroEL, which functions 
with GroES (Fayet et al. 1989); and DnaK which usually acts with DnaJ and GrpE (Alfano and McMaken 1989; Dodson et al. 1989; Straus et al. 1990; Liberek et al. 1991). Two pieces of evidence suggest that HSPs also perform a chaperone function in protein export. First, the GroEL/GroES HSP complex appears to be the primary chaperone for the export of $\beta$-lactamase. groEL and groES mutants are defective in processing $\beta$-lactamase in vivo (Kusukawa et al. 1989) and the GroEL and GroES proteins are required for in vitro transport of this protein (Bochkareva et al. 1988; Laminet et al. 1990). Second, HSPs can substitute for the SecB chaperone and are required for cellular viability in the absence of a functional SecB protein (Altman et al. 1991).

Interestingly, there has been no evidence that DnaK plays a role in the export of normal proteins, although increased levels of DnaK (or GroEL and GroES) facilitate export of a LamB-LacZ hybrid protein (Phillips and Silhavy 1990). The lack of involvement of DnaK in protein export in prokaryotes was surprising because Hsp70s, the DnaK homologs in eukaryotic cells, participate in several aspects of protein transport. Mitochondrial Hsp70, together with cytoplasmic Hsp70, is involved in the initial step in mitochondrial import (Kang et al. 1990). In addition, a cytoplasmic Hsp70 (Deshaies et al. 1988) and dna/ homologs (Sadler et al. 1989; Atencio and Yaffe 1992) are required for protein transport through the endoplasmic reticulum.

In this report we have further investigated the role of DnaK in protein export. We find that DnaK and DnaJ are involved in export of $\mathrm{AP}$, a SecB-independent protein. Furthermore, we show that $\sec B$ null mutant strains require DnaK and Dnal for viability and for export of MBP and LamB, two SecB-dependent proteins.

\section{Results}

\section{DnaK and Dnal participate in the export of $A P$}

Although AP was the first periplasmic enzyme shown to be synthesized in a precursor form (Inouye and Beckwith 1977), its translocation pathway has not yet been fully established. AP is transported via the SecA export pathway (Oliver and Beckwith 1981), but $\sec B$ mutations have little effect on the rate of processing of pre-AP to the mature protein (Kumamoto and Beckwith 1985; Gannon et al. 1989) except at $30^{\circ} \mathrm{C}$ (Kusukawa et al.
1989); and no other chaperone has been implicated in its export.

Recently, we described dominant $d n a K$ mutations that result in partially functional DnaK proteins (Wild et al. 1992). We used the three mutations with the strongest phenotypes (EK171, GD229, and GD341) to determine whether the export of AP was dependent on DnaK. Whereas processing of AP in wild-type cells was almost complete after a 10-sec chase, two of the dnaK mutant strains (EK171 and GD229) processed AP very slowly (Fig. 1). The third mutant (GD341) exhibited a wild-type processing rate (data not shown). The greatest defect in processing was exhibited by EK171, which required 5 min to process $50 \%$ of the pre-AP to the mature form. In GD229, 30\% of AP remained unprocessed even after a 2.5-min chase (Fig. 1). These results suggest a role for DnaK in the export of AP.

DnaK often works in concert with two other HSPs, DnaJ and GrpE. DnaJ and GrpE not only modulate the activity of DnaK (Liberek et al. 1991) but may also interact directly with the target proteins (Alfano and McMacken 1989; Dodson et al. 1989; Zylicz et al. 1989; S. Wickner et al. 1991). We therefore determined whether dnaI and grpE mutations affected AP processing. We found that the dnal mutant HQ33 exhibited a defect in AP processing (Fig. 1). Although the effect of the dna) mutation was not as severe as those exhibited by dnaK mutations, these results suggest that Dnal is involved in the processing of AP. In contrast, grpE280 (Saito and Uchida 1977; Ang et al. 1986) did not exhibit a defect in AP processing (Fig. 1).

We have also examined the kinetics of processing of pre-RBP, a periplasmic protein that is believed, by a variety of criteria, to be exported independently of SecB (Collier et al. 1990). Neither the dnaK, dnal, and grpE mutations, described above, nor the groES30 or groEL140 mutations affect processing of this protein (data not shown). Either export of pre-RBP is chaperone independent, or a different chaperone is involved in maintaining the translocation-competent form of this precursor.

\section{DnaK and Dnal are required in strains lacking $\operatorname{Sec} B$}

The growth and protein export properties of $\sec B:$ Tn5, a strain that lacks SecB, have been characterized extensively. Two of its properties, which may be related, are

Figure 1. Processing of alkaline phosphatase in mutant strains. Cells growing exponentially in glycerol medium at $30^{\circ} \mathrm{C}$ were pulse-labeled for $15 \mathrm{sec}$ with Tran ${ }^{35}$ S-label (ICN), chased with nonradioactive amino acids for indicated times, immunoprecipitated with anti-AP antibody, and subjected to electrophoresis on $10 \%$ SDS-polyacrylamide gels to display the unprocessed (pre-AP) and mature (AP) forms of alkaline phosphatase.

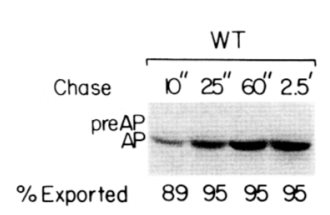

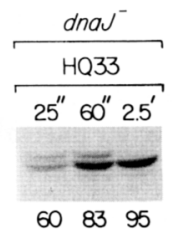

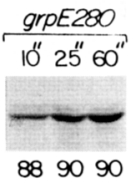


surprising. First, SecB-dependent proteins are still exported, albeit at reduced rates. Second, the growth defect of $\sec B$ strains is manifested only in rich medium (Kumamoto and Beckwith 1985). This growth defect is suppressed when HSPs are overproduced by increasing expression of $\sigma^{32}$. This observation suggests that some HSPs can substitute for the SecB function by acting as "backup chaperones" (Altman et al. 1991). The level of HSPs in the $\sec B$ null mutant may be sufficient to permit growth and protein export in minimal but not rich medium.

We considered the possibility that DnaK and DnaJ might be the HSPs substituting for the SecB function. If so, severe dnaK and dnaI mutations should be lethal when combined with a $\sec B$ null mutation. This proved to be the case. It was impossible to construct a $\sec B: \operatorname{Tn} 5$ strain that contained a $\Delta d n a J$ allele, although the isogenic $\sec B^{+}$strain was perfectly viable when deleted for dnaI (data not shown). Likewise, when the $\sec B:: \operatorname{Tn} 5$ insertion was transduced into the GD229 and EK171 dnaK mutants, 10 -fold fewer transductants were recovered. All of the transductants, unlike the recipient strain, grew in rich medium. The simplest explanation of these results is that the transductants had acquired a suppressor mutation that simultaneously permitted viability of the $\sec B:: \operatorname{Tn} 5$ dnaK strain in minimal medium and growth in rich medium. Consistent with this interpretation, when these double mutant strains were retransduced to $d n a K^{+}$, the resulting $\sec B:: \operatorname{Tn} 5$ transductants grew in rich medium. In contrast, a $\sec B: \operatorname{Tn} 5$ grpE280 double mutant strain was viable and retained typical SecB phenotypes. These results suggest that DnaK and DnaJ are required for the viability of a $\sec B:: \operatorname{Tn} 5$ strain.

To further investigate the role of the DnaK and DnaJ proteins in cells lacking $\operatorname{Sec} B$, we used a $\sec B:: \operatorname{Tn} 5$ strain in which all synthesis of DnaK and most synthesis of DnaJ was under control of the IPTG-inducible PlacUV5 (for details, see Materials and methods). Thus, we could create a conditional deficiency of DnaK and DnaJ by removal of IPTG, after which the synthesis of DnaK and DnaJ from PlacUV5 was shut off and the concentration of these proteins was lowered by cell growth. First, we examined the effect of depletion of DnaK and DnaJ on the growth of the $\sec B:: \operatorname{Tn} 5$ and $\sec B^{+}$strains. The growth rate of the $\sec B:: \operatorname{Tn} 5$ strain slowed dramatically about four doublings after removal of IPTG, whereas that of $\sec B^{+}$remained unaffected even more than six doublings after the removal of IPTG (Fig. 2). Consistent with these results, $\sec B:: \operatorname{Tn} 5$ cells depleted for DnaK and DnaJ exhibited a plating efficiency of $<10^{-6}$ on glycerol plates in the absence of IPTG, whereas the isogenic $\sec B^{+}$strain plated with an efficiency of $\sim 10^{-1}$. The more severe effect of depleting DnaK and DnaJ from $\sec B^{-}$strains than from $\sec B^{+}$strains indicates that DnaK and Dnal proteins play additional roles in a strain lacking SecB besides their functions in wild-type cells.

It was most likely that DnaK and DnaJ participated in the protein export process in $\sec B:: \operatorname{Tn} 5$ cells. We therefore examined the effect of depletion of DnaK and Dnal on this process. Continued synthesis of DnaK and DnaJ was



Figure 2. Growth of $\sec B:: \operatorname{Tn} 5$ and $\sec B^{+}$strains depleted for DnaK and DnaJ. CAG13522 (secB::Tn5 $\Delta d n a K d n a /$ pAKL1) and CAG13553, an isogenic $\sec B^{+}$strain were grown exponentially at $30^{\circ} \mathrm{C}$ in glycerol $/$ maltose $/$ Amp medium supplemented with IPTG to induce transcription of the dnaKJ operon controlled by PlacUV5 carried on pAKL1. At $A_{450}=0.2$, cells were filtered to remove IPTG and resuspended in medium lacking IPTG for continued growth. $A_{450}$ of the $\operatorname{secB}:: \operatorname{Tn} 5$ strain CAG13522 and the $\sec B^{+}$strain CAG13553 $(O)$ is shown as a function of time after removal of IPTG.

needed for the $\sec B:: \operatorname{Tn} 5$ strain to export some SecBdependent proteins. The processing of $L a m B$ and MBP was visibly slowed by two doublings after removal of IPTG. By three doublings, only $33 \%$ of LamB and $22 \%$ of MBP was processed (Fig. 3A). In contrast, OmpA exhibited only a slight retardation in processing, first observable at four doublings after removal of IPTG (Fig. 3A). Depletion of DnaK and DnaJ in the isogenic $\sec B^{+}$derivative had no effect on the processing of these three proteins (Fig. 3B).

\section{Overproduction of DnaK and Dnal partially substitutes for lack of $\operatorname{Sec} B$}

Since we showed that DnaK and Dnal were required for the viability of a $\sec B$ null strain on minimal medium, we tested whether overproduction of DnaK and DnaJ would suppress the lethality of $\sec B:: \operatorname{Tn} 5$ on rich medium. To achieve overproduction, we used a strain that retained the chromosomal copy of the $d n a K /$ operon and, in addition, carried the pAKLl plasmid allowing IPTGinducible expression of the $d n a J K$ genes. Upon induction of DnaK and DnaJ synthesis, the $\operatorname{secB}:: \mathrm{Tn} 5$ strain was able to grow in rich medium with $100 \%$ plating effi- 
A

Figure 3. Processing of $\mathrm{LamB}$ and MBP in strains depleted for DnaK and DnaJ. The secB::Tn5 strain CAG13522 $(A)$ and the isogenic $\sec B^{+}$ strain CAG13553 $(B)$, grown and depleted for DnaK and DnaJ as described in Fig. 2, were labeled with Tran $^{35} \mathrm{~S}$-label for $30 \mathrm{sec}$ and chased for 5 min with nonradioactive amino acids immediately before removal of IPTG and at 1,2,3, and 4 doublings $\left(>6\right.$ doublings for $\sec B^{+}$strain) after removal of IPTG. Samples were processed to detect and quantify the precursor and mature forms of LamB, MBP, and OmpA.

B
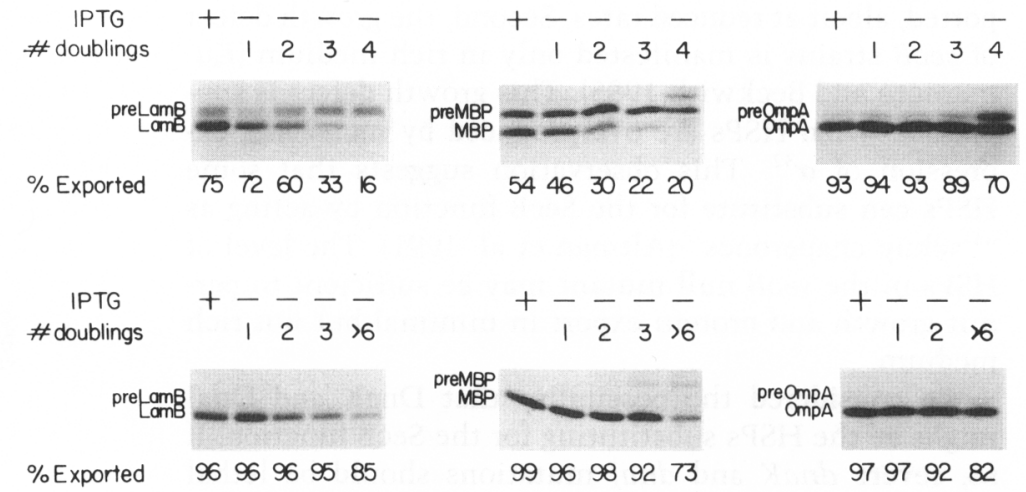

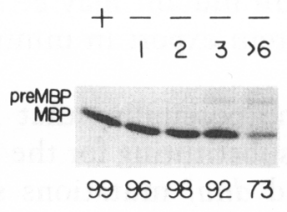

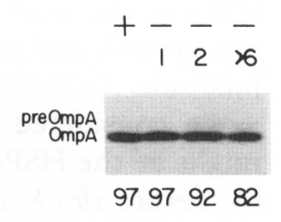

ciency (Fig. 4), but with a growth rate slower than that of $\sec B^{+}$(data not shown). These results suggest that increased amounts of DnaK and DnaJ partially substitute for the function of SecB. In agreement with previous results, the rich medium growth defect of the $\sec B: \operatorname{Tn} 5$ strain was not relieved by overproduction of DnaK alone (Altman et al. 1991). Suppression of rich medium growth defect of $\sec B:: \operatorname{Tn} 5$ by the overproduction of DnaK and DnaJ was strain dependent and occurred in MCl061 (used throughout this study) and MG1655 (Bachmann 1987) but not in C600 (Bachmann 1987) or MC4100 (Casadaban 1976). We have no clear explanation for the strain dependence we observe. However, because the $\sec B$ null mutation is deleterious for growth, different strain backgrounds may accumulate different low-level suppressors. These suppressors may affect the ability of DnaK and DnaJ to compensate for the $\sec B: \operatorname{Tn} 5$ secretion defect.

Increased amounts of DnaK and DnaJ presumably permitted growth of the $\sec B:$ Tn5 strain in rich medium because their overproduction compensated more effectively for the lack of SecB. In this case, overproduction of DnaK and DnaJ should result in an increase in the rate of export of at least some SecB-dependent proteins. The processing of two SecB-dependent proteins, LamB (Fig. $5 \mathrm{~A}, \mathrm{~B})$ and $\mathrm{MBP}$ (Fig. 6A-C) was facilitated by overpro-

duction of DnaK and DnaJ, whereas that of OmpA was not (Fig. 7). The time required to process half of the preLamB to the mature form $\left(t_{1 / 2}\right)$ was $3.6 \mathrm{~min}$ in $\sec B:: \operatorname{Tn} 5$ cells; upon overproduction of DnaK and DnaJ, the $t_{1 / 2}$ decreased to $2.4 \mathrm{~min}$ (Fig. $5 \mathrm{~A}, \mathrm{~B}$ ). For pre-MBP, the processing kinetics were biphasic (Fig. 6A,B). The second phase of the reaction $\left(t_{1 / 2}=50 \mathrm{~min}\right)$ corresponded to the degradation of pre-MBP, as there was not a corresponding increase in the absolute amount of the mature form during this time period (Fig. 6A). By subtracting the degradation component of the reaction, the processing component was observed directly (Fig. $6 \mathrm{C}$ ). In the case of MBP, overproduction of DnaK and DnaJ not only accelerated the initial rate of processing but also permitted it to proceed for a longer time. The net result is that almost twice as much MBP was exported when DnaK and Dnal were overproduced (Fig. 6C). Such a result is not surprising. If cells with higher levels of DnaK and DnaJ maintain pre-MBP in an export-competent state for a longer time than those with lower levels, effective processing can occur over a longer time frame. Thus, overproducing DnaK and Dnaj not only will affect the rate of export but also, and possibly more significantly, the amount of the precursor protein that is transported to its proper location.

Figure 4. Growth of a $\sec B:: \operatorname{Tn} 5$ strain in rich medium after overproduction of DnaK and DnaJ. CAG13471 (secB::Tn5 pAKL1) grown overnight at $30^{\circ} \mathrm{C}$ in glycerol $/ \mathrm{mal}$ tose/Amp/IPTG medium was diluted $10^{5}$. fold and plated on LB-Amp plates with (right) or without (left) $0.2 \mathrm{mM}$ IPTG to induce the dnaKJ operon carried on pAKL1. Control platings indicate that the induced culture exhibited $100 \%$ plating efficiency, whereas the uninduced culture had a plating efficiency of $<10^{-6}$.

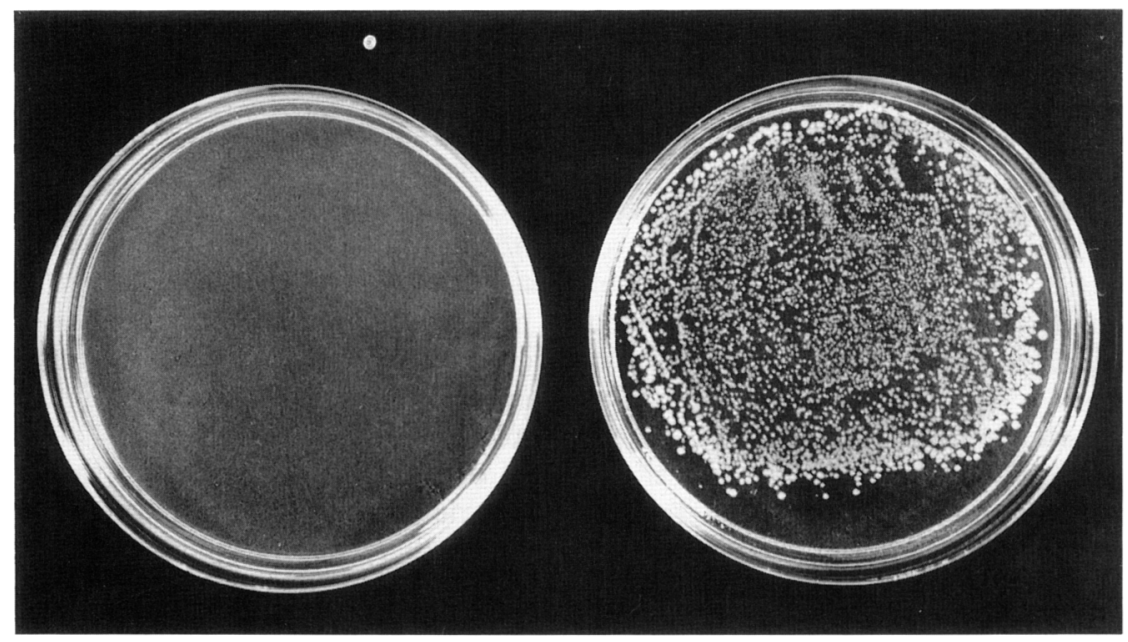


A

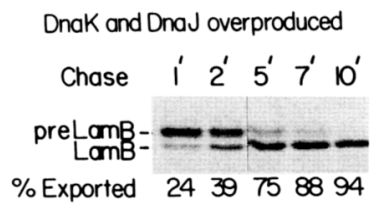

Dnak and DnaJ not overproduced

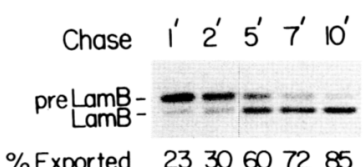

B

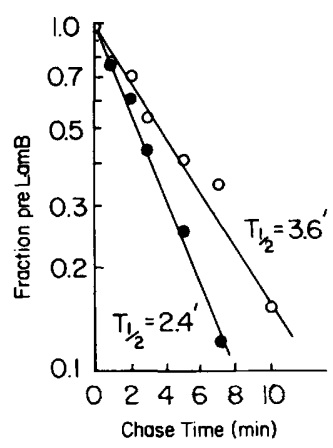

Figure 5. Processing of LamB upon overproduction of DnaK and Dnal in a $\sec B:: \operatorname{Tn} 5$ strain. $\sec B:: \operatorname{Tn} 5$ and $\sec B^{+}$strains growing exponentially in glycerol/maltose/Amp/IPTG medium were pulse-labeled for $30 \mathrm{sec}$ with $\operatorname{Tran}^{35} \mathrm{~S}$-label, chased with nonradioactive amino acids for the time periods indicated, and processed to detect and quantify precursor and mature LamB. $(A)$ Conversion of pre-LamB to LamB. (Top) Disappearance of pre-LamB upon overproduction of DnaK and DnaJ [CAG13471 (secB::Tn5 pAKLl)]; (bottom) disappearance of preLamB without overproduction of DnaK and Dna] [CAG13469 (secB::Tn5 pB10a)]. (B) The kinetics of pre-LamB processing. The fraction of pre-LamB protein present in CAG13471 (O) and CAG13469 (O) at each time point was calculated from the data in Fig. 5A and plotted as a function of the time of chase.

\section{Discussion}

Our results establish that DnaK and DnaJ participate in the process of protein export in E. coli. Both proteins play a primary role in the export of $\mathrm{AP}$ and a secondary role in the export of some SecB-dependent proteins. These results complement previous studies that have established a role for Hsp70 proteins and homologs of DnaJ in several aspects of the secretion process in eukaryotic cells (Deshaies et al. 1988; Sadler et al. 1989; Kang et al. 1990; Atencio et al. 1992). Our results to date using the grpE280 mutant do not indicate a role for GrpE either in export of AP or in processing of SecB-dependent proteins. However, this strain still retains some GrpE function, as judged by the fact that deletion mutants of $g r p E$ are inviable (Fayet et al. 1989). Therefore, additional approaches will be required to determine whether GrpE is also involved in protein export.

\section{DnaK and Dnal participate in the export of $A P$}

The delay in processing pre-AP to the mature form in dnaK and dnaJ mutants implicates DnaK and DnaJ in AP export. DnaK and DnaJ could participate directly in AP secretion by being the chaperones that maintain the precursor protein in a transport-competent state. Although direct evidence will be required to establish whether DnaK and DnaJ interact with pre-AP, our results are consistent with this possibility. First, not all dnaK mutations affect AP export. Thus, impaired processing is unlikely to be a consequence of global changes in gene ex-

pression, such as increased expression of the HSPs, characteristic of all dnaK mutants examined to date. Second, the extent of the processing defect is allele specific, as would be expected if the mutant proteins affect the interaction of DnaK with AP in different ways. Finally, the processing defect is specific to AP and does not result from "jamming" the export machinery, as several other proteins (RBP, MBP, LamB, and OmpA) exhibited normal kinetics of export in the mutant strains /data not shown).
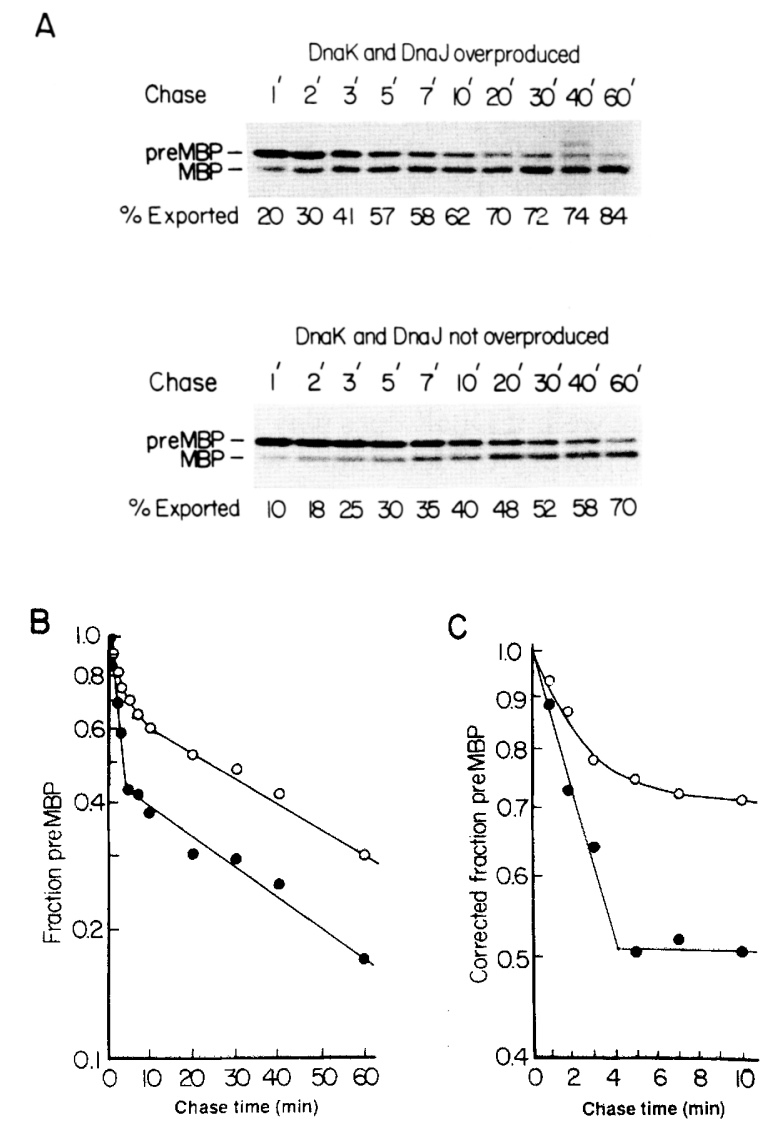

Figure 6. Processing of MBP upon overproduction of DnaK and DnaJ in a secB::Tn5 strain. Strains CAG13471 and CAG13469, grown and labeled as in Fig. 5, were processed to detect and quantify precursor (pre-MBP) and mature MBP. $(A)$ Conversion of pre-MBP to MBP. (Top) Disappearance of pre-MBP upon overproduction of DnaK and Dnal [CAG13471 (secB::Tn5 pAKL1)]; (bottom) disappearance of pre-MBP without overproduction of DnaK and Dnal [CAG13469 (secB::Tn5 pB10a)]. (B) Kinetics of disappearance of pre-MBP. The fraction of pre-MBP present in CAG13471 (O) and CAG13469 (O) at each time point was calculated from the data in $(A)$ and plotted as a function of the time of chase. The slow phase of the curves $\left(t^{1 / 2} \sim 50 \mathrm{~min}\right)$ represents degradation of pre-MBP as there is no increase in the absolute amount of MBP. $(C)$ Kinetics of processing of pre-MBP. To determine the processing component of the disappearance of preMBP at early times, the degradation component (determined by back-extrapolating the late time points in Fig. 6B) was subtracted. Disappearance of pre-MBP protein resulting only from processing in CAG13471 (O) and CAG13469 (O) is plotted as a function of the time of chase. 
Wild et al.

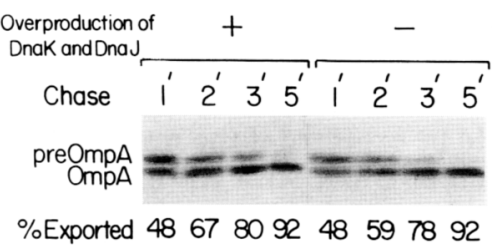

Figure 7. Processing of OmpA in $\sec B:: \operatorname{Tn} 5$ strain overproducing DnaK and DnaJ. Disappearance of pre-OmpA in strain CAG13471 (lanes 1-4) and CAG13469 (lanes 5-8) grown and labeled as in Fig. 5, and processed to detect and quantify precursor (pre-OmpA) and mature OmpA.

The AP precursor in the cytoplasm may be a favored substrate for binding DnaK because it is more unfolded than other precursor proteins such as pre-MBP (Derman and Beckwith 1991). The dominant-negative DnaK variants could be defective in releasing the bound AP precursors. Kusukawa et al. (1989) noted that export of AP is retarded in the $\sec B:: \operatorname{Tn} 5$ mutant at $30^{\circ} \mathrm{C}$ but not at $42^{\circ} \mathrm{C}$. Thus, at low temperature, when only basal levels of DnaK and DnaJ are present, SecB may participate in AP export as well. If DnaK does play a chaperone role, it will be interesting to determine whether DnaK, like SecB, helps target precursor proteins to the translocase or functions solely to maintain them in an export-competent conformation.

\section{The role of DnaK and Dnal in a strain lacking $S e c B$}

We have established a role for the DnaK and Dnal proteins in the viability and protein export process of cells lacking SecB. In reciprocal experiments, we showed that overproduction of DnaK and DnaJ allowed a $\sec B$ null strain to grow in rich medium and accelerated the export rates of MBP and LamB. Using a $\sec B:: \operatorname{Tn} 5$ strain in which all expression of $d n a K$ and most expression of dnaI was driven by the IPTG-inducible lacUV5 promoter, we were able to show that depleting DnaK and DnaJ reduced export of MBP and LamB, impaired growth rate, and reduced the viability of these cells dramatically. No such defects in export or growth were observed in $\sec B^{+}$cells. Among other possiblities, the decrease in growth rate could be a consequence of "jamming" the protein export machinery several doublings after specific export defects first become evident. In this case, accumulation of pre-OmpA, observed only when the growth rate of the culture declined, could result from jamming the protein export machinery. Taken together, these data indicate that DnaK and DnaJ can partially substitute for several of the functions of SecB.

Our depletion experiments indicate that strains lacking SecB require elevated levels of DnaK and Dnal to be able to grow in minimal medium. In these experiments, DnaK and DnaJ were initially supplied at a level sixfold higher than that in wild-type cells (data not shown). Secretion defects were already observed two doublings after shut-off of DnaK and DnaJ synthesis when the amount of DnaK is still greater than that in wild-type strains. These findings are in accord with our observa- tion that the amount of DnaK and Dnal is about five- to sixfold higher in the $\sec B:: \operatorname{Tn} 5$ mutant than in the isogenic wild-type strain (J. Wild, E. Altman, W. Walter, and C. Gross, in prep.).

Our experiments suggest an important role for DnaK and DnaJ in $\sec B^{+}$cells even though depleting DnaK and DnaJ had little effect on the export of SecB-dependent proteins in $\sec B^{+}$cells during steady-state growth. The high rate of HSP synthesis in a $\sec B$ null strain indicates that the rate of synthesis of DnaK and DnaJ is responsive to the accumulation of precursor proteins. Most likely, the accumulated precursor proteins deplete DnaK and DnaJ from the cell, preventing them from carrying out their normal function of negatively regulating the synthesis of $\sigma^{32}$. The consequent accumulation of $\sigma^{32}$ results in increased expression of the HSPs. This points to a very interesting scenario. There is currently no evidence that the rate of synthesis of $\sec B$ is sensitive to accumulation of precursor proteins. Thus, if SecB became limiting, as it would be, for example, immediately after massive induction of some transport systems, precursor proteins would accumulate and the cell could respond by overproducing DnaK and DnaJ to facilitate the transport of these proteins.

The role of DnaK and Hsp70 as regulators of the heat shock response has been widely studied (Lindquist 1986; Stone and Craig 1990; Straus et al. 1990). There is increasing evidence that DnaK (together with Dnal and GrpE) acts as a cellular thermometer by regulating the stability, synthesis, and activity of $\sigma^{32}$ in response to the availability of its substrates (for review, see Craig and Gross 1991). Our studies on the involvement of DnaK in protein secretion suggests that it may actually have a much wider sensory role in the cell. The ability of the pool of DnaK and DnaJ to change in response to varying levels of its substrates may not only maintain a reasonable rate of protein secretion under diverse sets of conditions but may also allow a number of other cellular processes involving DnaK to respond to environmental change [e.g., flagella formation, proteolysis, and replication of the E. coli, $\lambda, \mathrm{P} 1$, and F plasmid DNAs |for review, see Georgopoulos et al. 1990; Gross et al. 1990)]. From this point of view, DnaK may be a master regulator that functions to coordinate the activity of a wide variety of proteins to maintain balanced growth in a fluctuating environment.

\section{Materials and methods}

Bacterial strains, plasmids, and genetic methods

All strains employed were derivatives of MC1061 [araD139 $\Delta$ (ara-lac)7679 $\Delta$ lacX74 galK galU mcrB hsdR rpsL thi] [Casadaban and Cohen 1980). CAG13469 is secB::Tn5 pB10a; CAG13471 is $\operatorname{secB}:$ Tn5 pAKLl; CAG13553 is $\sec B^{+} \Delta d n a K J$ thrTn10 pAKL1; CAG13522 is secB::Tn5 $\Delta$ dnaKJ thrTn10 pAKL1. The original secB::Tn5 insertion is MM152 (Kumamoto and Beckwith 1985). Strains used in experiments on AP processing contained the phoS21 mutation (obtained as BW3890 from B. Wanner), which synthesizes AP constitutively.

The $\mathrm{pB} 10$ a vector is a $\mathrm{pBR} 322$ derivative carrying the $l a c I^{q}$ gene and the IPTG-inducible lacUV5 promoter, followed by the 
XhoI and HindIII restriction endonuclease cloning sites. pNRK411 (kindly provided by N. Kusukawa) was derived by fusing $900 \mathrm{bp}$ of the $5^{\prime}$ end of dnaK to placUV5 on pB10a. pAKL1 is a pB10a derivative carrying the promoterless dnaKJ operon fused to the IPTG-inducible lacUV5 promoter. It was constructed by subcloning an EcoRI fragment of pJW4 containing the $3^{\prime}$ end of $d n a K$ and the entire dnal gene (Wild et al. 1992) into pNRK411. In pAKLl, all synthesis of $d n a K$ is under control of PlacUV5; however, a low level of the dnal transcription originates from a weak, internal promoter (Ohki et al. 1986).

Cells were grown in LB or in M9 minimal medium supplemented with $0.5 \%$ glycerol and all amino acids except L-methionine and L-cysteine. When indicated, glycerol medium was supplemented with $0.2 \%$ maltose, $0.2 \mathrm{~mm}$ IPTG, and $50 \mu \mathrm{g} / \mathrm{ml}$ of ampicillin (Amp). Transformations and phage P1 transductions were as described (Silhavy et al. 1984). The dnaK and dnaI mutations were isolated by selecting for mutants exhibiting elevated HSP synthesis (Wild et al. 1992) and are designated with a one-letter code. The first letter denotes the amino acid in the wild-type strain, the second the mutational change, and the number indicates the location of the change within the protein.

\section{Depletion of DnaK and Dnar}

CAG13553 (secB ${ }^{+} \Delta d n a K J$ thrTn10 pAKL1) and CAG13522 (secB::Tn5 $\Delta d n a K J$ thr Tn10 pAKL1) were grown at $30^{\circ} \mathrm{C}$ to $\mathrm{A}_{450}=0.2$ in glycerol medium supplemented with maltose, IPTG, and Amp. To shut off the induced synthesis of DnaK and DnaJ from the lacUV5 promoter that drives expression of the dnaKdnal operon on pAKL1, IPTG was removed by filtering the cultures onto sterile nitrocellulose filters and washing the cells with 15 volumes of glycerol medium. Washed cells were resuspended in $10 \mathrm{ml}$ of prewarmed glycerol medium supplemented with maltose and Amp and grown at $30^{\circ} \mathrm{C}$ with aeration. Samples were withdrawn periodically for growth measurements and labeling. Immunoprecipitations with DnaK antisera indicated that no further DnaK synthesis was detectable after removal of IPTG. Preexisting DnaK and DnaJ were diluted by growth in the absence of IPTG.

\section{Radiolabeling, immunoprecipitation, and electrophoresis}

One-milliliter samples of cells growing exponentially at $30^{\circ} \mathrm{C}$ in glycerol medium were pulse-labeled with $60 \mu \mathrm{Ci} / \mathrm{ml}$ of $\operatorname{Tran}^{35}$ S-label (ICN; $1000 \mathrm{Ci} / \mathrm{mmole}$ ), chased with a nonradioactive mixture of L-methionine and L-cysteine $(200 \mu \mathrm{g} / \mathrm{ml})$, and precipitated with TCA as described (Grossman et al. 1987). The precursor and mature forms of $\mathrm{LamB}, \mathrm{MBP}, \mathrm{OmpA}, \mathrm{AP}$, and RBP were immunoprecipitated (Ito et al. 1981), resolved by electrophoresis on $10 \%$ SDS-polyacrylamide gels (Laemmli 1970), detected by autoradiography, and quantified with an Ambis Scanner interfaced with an IBM computer. Percent exported protein was calculated as mature protein/(mature + precursor protein). Antisera against AP were obtained from 5 Prime- 3 Prime, Inc. (West Chester, PA).

\section{Acknowledgments}

We thank B. Wanner for supplying strain BW3890, N. Kusukawa for pNRK411, and E. Craig, H. Echols, A. Kamath, and K. Ito for comments on the manuscript. Antisera against OmpA, RBP, and MBP were kindly provided by J. Beckwith. This work was supported by U.S. Public Health Research grant GM36278 from the National Institutes of Health to C.A.G.

The publication costs of this article were defrayed in part by payment of page charges. This article must therefore be hereby marked "advertisement" in accordance with 18 USC section 1734 solely to indicate this fact.

\section{References}

Alfano, C. and R. McMacken. 1989. Ordered assembly of nucleoprotein structures at the bacteriophage $\lambda$ replication origin during the initiation of DNA replication. I. Biol. Chem. 246: 10699-10708.

Altman, E., C.A. Kumamoto, and S.D. Emr. 1991. Heat-shock proteins can substitute for $\mathrm{SecB}$ function during protein export in Escherichia coli. EMBO /. 10: 239-245.

Ang, D., G.N. Chandrasekhar, M. Zylicz, and C. Georgopoulos. 1986. Escherichia coli grpE gene codes for heat shock protein B25.3, essential for both $\lambda$ DNA replication at all temperatures and host growth at high temperature. J. Bacteriol. 167: 25-29.

Atencio, D.P. and M.P. Yaffe. 1992. MAS5, a yeast homolog of Dnal involved in mitochondrial protein import. Mol. Cell. Biol. 12: 283-291.

Bachmann, B.J. 1987. Derivations and genotypes of some mutant derivatives of Escherichia coli K-12. In Escherichia coli and Salmonella typhimurium: Cellular and molecular biology. (ed. F.C. Neidhardt, J.L. Ingraham, K.B. Low, B. Magasanik, M. Schaechter, and H.E. Umbarger), pp. 1190-1219. American Society for Microbiology, Washington, D.C.

Bieker, K.L. and T.J. Silhavy. 1990. PrlA (SecY) and PrlG (SecE) interact directly and function sequentially during protein translocation in E. coli. Cell 61: 833-842.

Bochkareva, E.S., N.M. Lissin, and A.S. Girshovich. 1988. Transient association of newly synthesized unfolded proteins with the heat-shock GroEL protein. Nature 336: 254-257.

Casadaban, M. 1976. Transposition and fusion of the lac gene to selected promoters in Echerichia coli using bacteriophage lambda and Mu. J. Mol. Biol. 104: 541-555.

Casadaban, M. and S.N. Cohen. 1980. Analysis of gene control signals by DNA fusion and cloning in Escherichia coli. $J$. Mol. Biol. 138: 179-207.

Collier, D.N., V.A. Bankaitis, J.B. Weiss, and P.J. Bassford, Jr. 1988. The antifolding activity of SecB promotes the export of the E. coli maltose-binding protein. Cell 53: 273-283.

Collier, D.N., S.M. Strobel, and P.J. Basford Jr. 1990. SecB-Independent export of Escherichia coli ribose-binding protein (RBP): Some comparisons with export of maltose-binding protein (MBP) and studies with RBP-MBP hybrid proteins. I. Bacteriol. 172: 6875-6884.

Craig, E.A. and C.A. Gross. 1991. Is hsp70 the cellular thermometer? Trends Biochem. Sci. 16: 135-140.

Derman, A.I. and J. Beckwith. 1991. Escherichia coli phosphatase fails to acquire disulfide bonds when retained in the cytoplasm. I. Bacteriol. 173: 7719-7722.

Deshaies, R.J., B.D. Koch, M. Werner-Washburne, E.A. Craig, and R. Schekman. 1988. A subfamily of stress proteins facilitates translocation of secretory and mitochondrial precursor polypeptides. Nature 332: 800-805.

Dodson, M., R. McMacken, and H. Echols. 1989. Specialized nucleoprotein structures at the origin of replication of bacteriophage $\lambda$. I. Biol. Chem. 246: 10719-10725.

Fayet, O., T. Ziegelhoffer, and C. Georgopoulos. 1989. The groES and groEL heat shock gene products of Escherichia coli are essential for bacterial growth at all temperatures. J. Bacteriol. 171: 1379-1385.

Gannon, P.M., P. Li, and C.A. Kumamoto. 1989. The mature portion of Escherichia coli maltose-binding protein (MBP) determines the dependence of MBP on SecB for export. $/$. Bacteriol. 171: 813-818.

Gardel, C., K. Johnson, A. Jacq, and J. Beckwith. 1990. The secD locus of $E$. coli codes for two membrane proteins required for protein export. EMBO I. 9: 3209-3216.

Georgopoulos, C., D. Ang, K. Liberek, and M. Zylicz. 1990. 
Properties of the Escherichia coli heat shock proteins and their role in bacteriophage $\lambda$ growth. In Stress proteins in biology and medicine (ed. R.I. Morimoto, A. Tissières, and C. Georgopoulos|, pp. 191-221. Cold Spring Harbor Laboratory Press, Cold Spring Harbor, New York.

Gross, C.A., D.B. Strauss, and J.W. Erickson. 1990. The function and regulation of heat shock proteins in Escherichia coli. In Stress proteins in biology and medicine (ed. R.I. Morimoto, A. Tissières, and C. Georgopoulos), pp. 167-189. Cold Spring Harbor Laboratory Press, Cold Spring Harbor, New York.

Grossman, A.D., D.B. Straus, W.A. Walter, and C.A. Gross. 1987. $\sigma^{32}$ Synthesis can regulate the synthesis of heat shock proteins in Escherichia coli. Genes \& Dev. 1: 179-184.

Hardy, S.S. and L.L. Randall. 1991. A kinetic partitioning model of selective binding of nonnative proteins by the bacterial chaperone SecB. Science 251: 439-443.

Hartl, F.U., S. Lecker, E. Schiebel, J.P. Hendrick, and W. Wickner. 1990. The binding cascade of SecB to SecA to SecY/E mediates preprotein targeting to the $E$. coli plasma membrane. Cell 63: 269-279.

Inouye, H. and J. Beckwith. 1977. Synthesis and processing of alkaline phosphatase precursor in vitro. Proc. Natl. Acad. Sci. 74: 1440-1444.

Ito, K., P.J.J. Bassford, and J. Beckwith. 1981. Protein localization in E. coli: Is there a common step in the secretion of periplasmic and outer-membrane proteins? Cell 24: 707717.

Kang, P.J., J. Ostermann, J. Shilling, W. Neupert, E.A. Craig, and N. Pfanner. 1990. Requirement for hsp70 in the mitochondrial matrix for translocation and folding of precursor proteins. Nature 348: 137-142.

Kumamoto, C.A. 1989. Escherichia coli SecB protein associates with exported protein precursors in vivo. Proc. Natl. Acad. Sci. 86: $5320-5324$.

Kumamoto, C.A. and J. Beckwith. 1983. Mutations in a new gene, $\sec B$, cause defective protein localization in Escherichia coli. J. Bacteriol. 154: 253-260.

- 1985 . Evidence for specificity at an early step in protein export in Escherichia coli. J. Bacteriol. 163: 267-274.

Kumamoto, C.A. and P.M. Gannon. 1988. Effects of Escherichia coli $\sec B$ mutations on pre-maltose binding protein conformation and export kinetics. J. Biol. Chem. 263: 1155411558.

Kusukawa, N., T. Yura, C. Ueguchi, Y. Akiyama, and K. Ito. 1989. Effects of mutations in heat-shock genes groES and groEL on protein export in Escherichia coli. EMBO $J$. 8: 3517-3521.

Laemmli, U.K. 1970. Cleavage of structural proteins during the assembly of the head of bacteriophage T4. Nature 227: 680 685.

Laminet, A.A., T. Ziegelhoffer, C. Georgopoulos, and A. Plückthun. 1990. The Escherichia coli heat shock proteins GroEL and GroES modulate folding of the $\beta$-lactamase precursor. EMBO I. 9: 2315-2319.

Lecker, S.H., A.J.M. Driessen, and W. Wicker. 1990. ProOmpA contains secondary and tertiary structure prior to translocation and is shielded from aggregation by association with SecB protein. EMBO I. 9: 2309-2314.

Liberek, K., J. Marszalek, D. Ang, C. Georgopoulos, and M. Zylicz. 1991. Escherichia coli DnaJ and GrpE heat shock proteins jointly stimulate ATPase activity of DnaK. Proc. Natl. Acad. Sci. 88: 2874-2878.

Lill, R., K. Cunningham, L.A. Brundage, K. Ito, D. Oliver, and W. Wickner. 1989. SecA protein hydrolyzes ATP and is an essential component of the protein translocation ATPase of Escherichia coli. EMBO I. 8: 961-966.
Lill, R., W. Dowhan, and W. Wickner. 1990. The ATPase activity of SecA is regulated by acidic phospholipids, SecY, and the leader and mature domains of precursor proteins. Cell 60:271-280.

Lindquist, S. 1986. The heat shock response. Annu. Rev. Biochem. 55: 1151-1191.

Ohki, M., F. Tamura, S. Nishimura, and H. Uchida. 1986. Nucleotide sequence of the $E$. coli dnal gene and purification of the gene product. I. Biol. Chem. 261: 1778-1781.

Oliver, D.B. and J. Beckwith. 1981. E. coli mutant pleiotropically defective in the export of secreted proteins. Cell 25: 765-772.

Phillips, G.J. and T.J. Silhavy. 1990. Heat-shock proteins DnaK and GroEL facilitate export of LacZ hybrid proteins in $E$. coli. Nature 344: 882-884.

Sadler, I., A. Chiang, T. Kurihara, J. Rothblatt, J. Way, and P. Silver. 1989. A yeast gene important for protein assembly into the endoplasmic reticulum and the nucleus has homology to DnaJ, an Escherichia coli heat shock protein. J. Cell. Biol. 109: 2665-2675.

Saier, J.M.H., P.K. Werner, and M. Muller. 1989. Insertion of proteins into bacterial membranes: Mechanism, characteristics, and comparisons with the eucaryotic process. Microbiol. Rev. 53: 333-366.

Saito, H. and H. Uchida. 1977. Initiation of the DNA replication of bacteriophage lambda in Escherichia coli K12. J. Mol. Biol. 113: 1-25.

Schatz, P.J. and J. Beckwith. 1990. Genetic analysis of protein export in Escherichia coli. Annu. Rev. Genet. 24: 215-248.

Silhavy, T.J., M.L. Berman, and L.W. Enquist. 1984. Experiments with gene fusions. Cold Spring Harbor Laboratory, Cold Spring Harbor, New York.

Stone, D.E. and E.A. Craig. 1990. Self-regulation of 70-kilo-dalton heat shock proteins in Saccharomyces cerevisiae. Mol. Cell. Biol. 10: 1622-1632.

Straus, D., W. Walter, and C.A. Gross. 1990. DnaK, DnaJ, and GrpE heat shock proteins negatively regulate heat shock gene expression by controlling the synthesis of $\sigma^{32}$. Genes \& Dev. 4: 2202-2209.

Watanabe, M. and G. Blobel. 1989. Cytosolic factor purified from Escherichia coli is necessary and sufficient for the export of a preprotein and is a homotetramer of SecB. Proc. Natl. Acad. Sci. 86: 2728-2732.

Weiss, J.B. and P.J. Bassford Jr. 1990. The folding properties of the Escherichia coli maltose-binding protein influence its interaction with SecB in vitro. I. Bacteriol. 172: 3023-3029.

Weiss, J.B., P.H. Ray, and P.J. Bassford Jr. 1988. Purified SecB protein of Escherichia coli retards folding and promotes membrane translocation of the maltose-binding protein in vitro. Proc. Natl. Acad. Sci. 85: 8978-8982.

Wickner, S., J. Hoskins, and K. McKenny. 1991. Monomerization of RepA dimers by heat shock proteins activates binding to DNA replication origin. Proc. Natl. Acad. Sci. 88: 79037907.

Wickner, W., J.M. Driessen, and F.U. Hartl. 1991. The enzymology of protein translocation across the Escherichia coli plasma membrane. Annu. Rev. Biochem. 60: 101-124.

Wild, J., A. Kamath-Loeb, E. Ziegelhoffer, M. Lonetto, Y. Kawasaki, and C.A. Gross. 1992. Partial loss of function mutations in dnaK, the Escherichia coli hsp70 homologue, affect highly conserved amino acids implicated in ATP binding and hydrolysis. Proc. Natl. Acad. Sci. (in press).

Zylicz, M., D. Ang, K. Liberek, and C. Georgopoulos. 1989. Initiation of $\lambda$ DNA replication with purified host- and bacteriophage-encoded proteins: The role of the dnaK, dnaJ and grpE heat shock proteins. EMBO I. 8: 1601-1608. 


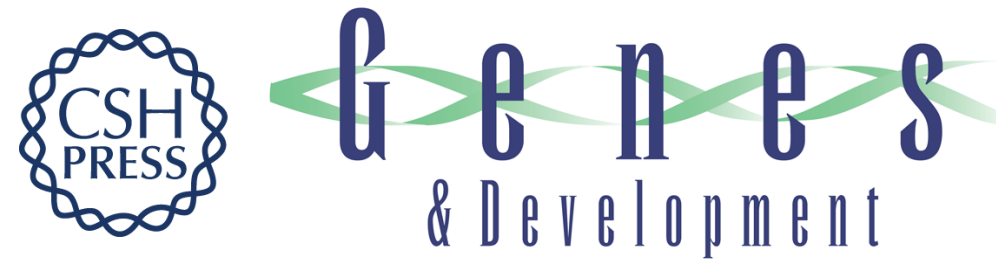

\section{DnaK and DnaJ heat shock proteins participate in protein export in Escherichia coli.}

J Wild, E Altman, T Yura, et al.

Genes Dev. 1992, 6:

Access the most recent version at doi:10.1101/gad.6.7.1165

References This article cites 50 articles, 23 of which can be accessed free at: http://genesdev.cshlp.org/content/6/7/1165.full.html\#ref-list-1

License

Email Alerting

Service

Receive free email alerts when new articles cite this article - sign up in the box at the top right corner of the article or click here.



